\title{
Penetapan Syari'at untuk Kemaslahatan Hamba di Dunia dan Akhirat
}

\author{
Muhammad Kasim
}

Abstrak

Al-quran merupakan kitab suci umat islam yang didalamnya memuat segala peraturan-peraturan tentang kehidupan manusia baik itu di dunia maupun diakhirat kelak, hal inilah kondisi dimana hukum dilahirkan dan kondisi hukum itu diterapkan adalah berbeda bagaimana mengaktualisasikan hukum Islam agar sesuai dengan Zaman dari tempatnya masing-masing.

Kata kunci: Syariat, Ijtihad

\section{A. Pendahuluan}

Islam adalah ajaran yang disampaikan oleh Nabi Muhammad saw. sebagai utusan Allah swt. di muka bumi ini dan beliau juga membawa petunjuk untuk sekalian manusia dalam mencapai kebahagiaan dunia dan akhirat, kesempurnaannya telah dijamin sebagaimana yang telah diwahyukan Allah swt dalam surat al-Ma'idah (5) : 3 yang berbunyi :

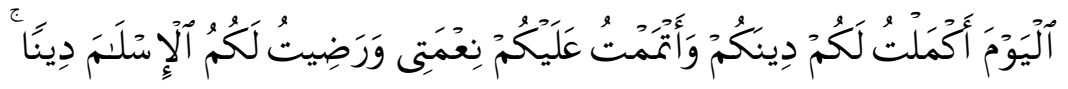

"Pada hari ini telah Kusempurnakan untuk kamu agamamu, dan telah Kucukupkan kepadamu nikmat-Ku, dan telah Ku-ridhai Islam itu Jadi agama bagimu"1

Kesempurnaan dalam hal ini, adalah mengacu pada ajaran-ajaran yang terkandung di dalamnya yang mengatur seluruh aspek kehidupan manusia. Kendatipun Islam sebagai ajaran agama, tetapi hukum pada pelaksanaannya tidak lepas dari perkembangan dari zaman ke zaman, sehingga banyak menimbulkan berbagai permasalahan (problematika) tersendiri, dan berbagai persoalanpersoalan yang bisa saja bermunculan, dikarenakan perkembangan dan perubahan yang cukup besar dalam berbagai lini kehidupan bermasyarakat. Untuk itulah Islam sebagai agama yang menyempurnakan agama-agama yang lain yang

\footnotetext{
${ }^{1}$ Kementrian Urusan Agama Islam, Wakaf, Da’wah dan Irsyad Kerajaan Saudi Arabia, Al-Qur'an dan Terjemahannya, (Madinah: Percetakan al-Qur'an al-Karim Raja Fahd, 1426H), h.157.
} 
bersifat global (universal) dapat berlaku umum pada semua zaman dan tempat sesuai dengan perkembangan yang terjadi.

Kitab al-Qur'an ${ }^{2}$ merupakan syari'at Islam yang bersifat menyeluruh, dan ia merupakan sumber dan rujukan yang pertama bagi syari'at, karena didalamnya terdapat kaidah-kaidah yang bersifat global beserta rinciannya.

Dari keuniversalan itulah, hukum Islam yang terkandung dalam alQur'an dan al-Sunnah tidak disebutkan secara rinci, dalam hal ini kondisi dimana hukum dilahirkan dan kondisi hukum itu diterapkan adalah berbeda bagaimana mengaktualisasikan hukum Islam agar sesuai dengan Zaman dari tempatnya masing-masing. Tidak ada jalan lain untuk menempuh hal ini kecuali dengan melakukan Ijtihad ${ }^{3}$ yang pada dasarnya setiap mujtahid diharapkan mengetahui arti syari'at dan menempatkan manusia sebagai ciptaan Allah swt dalam menjalani hidup di atas dunia dengan kapasitasnya untuk mengabdi kepada Allah swt, dengan jalan mengetahui tujuan syāri' menurunkan syariat kepada manusia.

\section{B. Pembahasan.}

\section{Definisi Maqasid al-Syari'ah.}

Kata Maqasid berasal dari kata قَصَدَ - قَقْصُدُ - قَصْدًا - و مَقْصَدًا yang bentuk

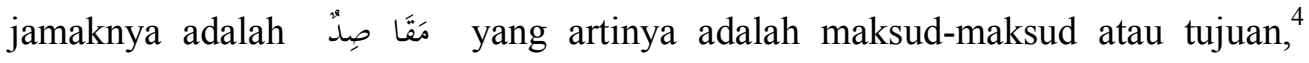
sedangkan al-Syari'ah secara etimologi, berasal dari kata dasar syara'a - yasyra'u - syar'an yang memiliki berbagai macam makna diantaranya, mengambil sesuatu

\footnotetext{
${ }^{2}$ Sumber Hukum yang pertama dari 4 sumber hukum, bahwa al-Qur'an itu datang dari Allah yang diwahyukan kepada Nabi Muhammad yang telah dipilih menjadi Rasul-Nya, dan merupakan sumber kepercayaan Agama, prinsip-prinsip Hukum dan peraturannya.

3 عبارة عن بذل البخهود واستفرا غ الوسع في تحقيق امر من الامور (upaya mengorbankan suatu kesungguhan dari menghabiskan waktu dalam menegakkan suatu urusan) Lihat Prof. DR. H. Minhajuddin, MA., Pengembangan Metode Ijtihad Dalam Perspektif Fikih Islam., Pidato Pengukuhan Guru Besar Tetap Dalam Ilmu Fikih / Usul fikih Pada Fakultas Syari'ah IAIN "Alauddin". Disampaikan pada Rapat Senat Terbuka Luar Biasa IAIN Alauddin Makassar hati/tanggal: Senin 31 Mei 2004.

${ }^{4}$ Ibrahim Mustafa., et. al., al-Mu'jam al-Wasit. Juz. II., (t.Cet; Istanbul: al-Maktabat al-Islamiyah, 1972M/1392H), h. 722., Lihat: Ensiklopedi Hukum Islam, Jilid 4., (Cet. V; Jakarta: PT. Ichtiar Baru van Hoeve, 2001), h, 1108.
} 
dari sumbernya, memunculkan dan menampakkan, menetapkan dan menjelaskan, dll.

syari'ah secara istilah menurut Mahmud Syaltut: "Peraturan yang diturunkan Allah agar dipedomani dalam berhubungan dengan Tuhannya, dengan sesamanya, dengan lingkungannya, dan dengan kehidupannya" 5 adalah sesuatu yang telah ditetapkan Allah atas hambanya pada masalah-masalah aqidah dan alahkam (hukum-hukum) ${ }^{6}$ Syari'ah dalam percakapan bangsa Arab adalah kumpulan atau sumber air yang dapat diminum oleh manusia dan hewan, serta sebagai irigasi. Dari makna-makna diatas al-Laits berkata: "dengan makna-makna tersebut, maka semua yang disyari'atkan Allah kepada hamba-hambanya adalah syari'ah, baik tentang puasa, shalat, haji, nikah, maupun yang lainnya". 7

Adapun ahli usul merumuskan bahwa syari'at adalah khitab syari' yang berkaitan dengan perbuatan-perbuatan para mukalaf yang mengandung tuntutan untuk dikerjakan atau memilih mengerjakan atau tidak mengerjakan. Atau ada sesuatu sebagai sebab, syarat atau penghalang ${ }^{8}$, maka dapatlah dikemukakan bahwa yang dimaksud syari'at adalah sekumpulan aturan atau ketentuan yang berisi perintah, larangan hukum, kemudian dijelaskan oleh Rasul-Nya untuk mengatur dan membina serta membatasi tindakan hamba-Nya untuk mencapai tujuan kehidupan, baik di dunia maupun di akhirat.

\section{Maksud Syarī’ dalam penetapan syari'at untuk kemaslahatan hamba-Nya.}

Pada dasarnya, penetapan Syari'at itu dangan maksud memberikan keselamatan pada hambanya yaitu saat sekarang (dunia) atau yang akan datang (akhirat) secara bersamaan, pendapat ini harus dibarengi dengan argumentasi yang kuat untuk membenarkannya atau menolaknya. Namun itu bukan pembahasannya disini. Karena terdapat perbedaan dalam Ilmu Kalam. al-Rāzi berpendapat : bahwasanya hukum-hukum Allah tidak ada hubungan dengan Qarinah (illat)

${ }^{5}$ Mahmud Syaltut, al-Islām aqidah wa Syāri’ah (Mesir: Dār al-Qalam, 1966), h. 12; lihat juga: Ahmad Rofiq, Hukum Islam di Indonesia, (Ed. I, Cet, 6; Jakarta: PT. RajaGrafindo Persada, 2003), h. 4

Ibrahim Mustafa, Ibid., h. 479

7 Abu al-Fadl Jamaluddin Muhammad Ibn Makram Ibn Mandz̄ūr ibn al-Afrīqi al Mişri, Lisān al-Arab, Juz. XIII., (Cet. III; Bairut: Dār al-Fikr, 1414 h/1994M), h. 175

${ }^{8}$ Al-Hudariy, Uşul al-fiqh, (Cet. III; Beirut: Dār al-Fikr, 1981), h. 88 
yang sudah disebutkan di atas, demikian juga dengan perbuatan-perbuatan Tuhan. Namun Mu'tazilah berpendapat (bersepakat) bahwa hukum-hukum Allah berhubungan dengan pengawasan terhadap kemaslahatan hamba dan ini adalah pendapat sebagian besar fuqaha modern. ${ }^{9}$

Dan yang menjadi patokan adalah bahwasanya syari'at itu ditetapkan untuk kemaslahatan hamba secara Istiqrā' (induktif). ${ }^{10}$ Dan pendapat ini tidak dibantah oleh al-Rāzi atau selainnya, sebab Allah berfirman tentang tujuan diutusnya para Rasul, dan ini adalah dasar syari'at, ${ }^{11}$ seperti dalam QS. al-Nisa' (4): 165.

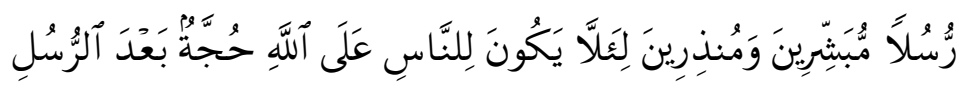

“(mereka Kami utus) selaku Rasul-rasul pembawa berita gembira dan pemberi peringatan agar supaya tidak ada alasan bagi manusia membantah Allah sesudah diutusnya Rasul-rasul itu". ${ }^{12}$

QS. al-Anbiya' (21): 107, Dan Allah berfirman tentang dasar penciptaannya yaitu dalam al-Qur'an Surat Hud (11) : 7, QS. al-Zariyat (21): 56.

Nash-nash yang ada dalam al-Qur'an dapat dimengerti apabila telah diketahui tujuan syar'i dalam mensyari'atkan hukum-hukumnya, seperti halnya pemerintah sebagai penguasa dalam meletakkan catatan-catatan berupa penafsiran yang menjelaskan tujuan diadakannya peraturan perundang-undangan secara umum dan secara khusus yang dituangkan dalam pasal-pasal, adalah untuk membantu masyarakatnya memahami dan menerapkannya dalam kehidupan sebagai warga negara.

Kemaslahatan manusia merupakan tujuan pelaksanaan syariat, hal ini sebagaimana yang termaktub dalam QS. al-Anbiya' (21): 107 yang artinya “ dan tiadalah Kami mengutus kamu, melainkan untuk (menjadi) rahmat bagi alam semesta", kata rahmat dalam ayat di atas, menurut para ahli ushul fiqh,

9 Abu Ishaq Ibrahim bin Musa al-lakhmi al-Garnathi al-Māliki al-Syāţibi., AlMuwāfakāt fi Uşuli al-Syāri'ah, Juz II., (t.Cet; Beirut: Dār al-Qutub al-ilimiyah, t.th), h. 4

${ }^{10}$ Ibrahim Mustafa., et. al., op.cit., h. 722

${ }^{11}$ al-Syāţibi., loc. cit.

${ }^{12}$ Kementrian Urusan Agama Islam, Wakaf, Da’wah dan Irsyad Kerajaan Saudi Arabia, op. cit., h. 151. 
mengandung pengertian bahwa pengutusan Rasul membawa kemaslahatan bagi umat manusia di dunia dan akhirat.

Kata maslahat secara etimologi berarti manfaat, dapat juga diartikan dengan suatu pekerjaan yang mengandung manfaat. Secara terminologi, diartikan dengan mengambil manfaat dari menolak kerusakan dalam rangka memelihara tujuan syarak.

Al-Syāţibi mengatakan syari'at itu diturunkan dengan tujuan memelihara maksud-maksud syar' $\bar{\imath}$ dalam penciptaan, maksud-maksud tersebut tidak terlepas dari tiga keadaan ${ }^{13}$ :

a. Sebagai kebutuhan al-darūriyyah. QS. al-Mumtahanah (60): 12 adalah kemaslahatan mendasar yang menyangkut dalam mewujudkan dan melindungi eksistensi kelima pokok ( agama, jiwa, akal, keturunan, dan harta), apabila kemaslahatan ini hilang, maka kehidupan manusia bisa hancur, tidak selamat, baik di dunia maupun di akhirat, atau penetapan syari'at itu harus bertujuan mendatangkan kemaslahatan Agama dan dunia dalam artian, jika tidak ada syari'at maka kemaslahatan duniawi tidak berlangsung bahkan munculnya kerusakan, fitnah dan kemungkaran serta hilangnya kehidupan. Adapun diakhirat hilangnya keberuntungan dan kenikmatan dan kembali kepada dengan kerugian yang nyata. Seperti: Dasar penetapan Ibadah, bertujuan untuk menjaga Agama seperti : Iman, dua kalimat syahadat, sholat, zakat, puasa, haji, dll. Adapun adat bertujuan untuk menjaga jiwa dan akal seperti : makan, minum, pakaian tempat tinggal, kenderaan, dll. Mua'amalah bertujuan untuk menjaga keturunan dan harta juga menjaga jiwa dan akal tetapi dengan perantaraan adat. Serta jinayah dan amal ma'ruf nahi mungkar itu bertujuan menjaga semua yang disebutkan tadi, atau dengan singkat dalam dikatakan bahwa: Tidak melakukan syirik (dalam rangka memelihara agama), Tidak mencuri (dalam rangka memelihara harta seseorang), tidak berzina (dalam rangka memelihara keturunan dan kehormatan seseorang), dan tidak

${ }^{13}$ Al-Syāţibi., Ibid. h. 7-9., Lihat juga: Dr. Abdul Karim Zaidan, al-Wajīzu fì Uşūli alFiqhi, (Cet. I; t.t.; Nasyru Ihsan, t.th), h. 381-382., Ensiklopedi Hukum Islam., op.cit. h. 11081112., Dr. H. Abdul Manan, SH., S.IP., M.Hum, Reformasi Hukum Islam di Indonesia, Ed.I., (Cet. I; Jakarta: PT. RajaGrafindo, 2006), h. 108-109. 
membunuh (dalam rangka memelihara jiwa orang lain). Jadi pada intinya masalah-masalah daruriyyah meliputi lima masalah Yaitu: menjaga agama, menjaga jiwa, menjaga keturunan, menjaga harta, dan menjaga akal. Dan jika diurut berdasarkan urutannya maka dimulai dengan agama, jiwa, akal, keturunan dan harta; berbeda dengan urutan diatas karena sebagian pendapat lebih mendahulukan menjaga jiwa dari pada agama. ${ }^{14}$

b. Sebagai kebutuhan al-häjiyyah. QS. al-Baqarah (2): 185 adalah dalam rangka perwujudan dan perlindungan yang diperlukan dalam melestarikan lima pokok tersebut di atas, tetapi kadar kebutuhannya berada di bawah kebutuhan aḍḍaūriyyah. Tidak terpeliharanya kebutuhan al-ḥājiyyat tidak akan membawa terancamnya eksistensi lima pokok tersebut, tetapi membawa kepada kesempitan dan kepicikan, baik dalam usaha mewujudkan maupun dalam pelaksanaannya, sedangkangkan dalam ajaran Islam kesempitan dan dan kepicikan itu perlu disingkirkan, atau penetapan syari'at sangat dibutuhkan untuk menghilangkan kesempatan yang berdampak pada kesusahan dan kemudhratan yang bergantung kepada tidak adanya hal yang dibutuhkan tersebut. Jika kebutuhan ini tidak terwujud maka kehidupan manusia akan mengalami kesulitan meskipun kehidupannya tidak sampai punah. Point ini juga meliputi : Ibadah (keringanan yang dibolehkan karna adanya kesulitan seperti sakit atau dalam perjalanan), Adat (dibolehkan berburu dan memakai wangi-wangian, makan, minum, pakaian, tempat tinggal dan berkenderaan, dll), Muamalat (al-qirāa $d^{15}$, musāqaț, al-silm, dan memakai metarai dalam aqad perjanjian jual beli) dan Jinayat.( beberapa penetapan diyat bagi 'aqilah).

c. Sebagai kebutuhan al-tahsin̄iyyah, dimaksudkan untuk mewujudkan dan memelihara hal-hal yang menunjang peningkatan kualitas ke lima pokok

${ }^{14}$ Al-Syāţibi, Ibid., h. 8

${ }^{15}$ Al-Qirad atau mudarabah adalah salah bentuk kerja sama antara pemilik modal dan seseorang yang ahli dalam berdagang yaitu : pemilik modal menyerahkan modalnya kepada pekerja (pedagang) untuk diperdagangkan, Sedangkan keuntungan dagang itu dibagi meneurut kesepakatan bersama, apabila terjadi kerugian dalam perdagangan tersebut kerugian ini ditanggung sepenuhnya oleh pemilik modal. Istilah qiradh ini dikemukakan oleh ulama Hijaz/hedzjaz, Sedangkan mudarabah adalah istilah dipakai oleh ulama Irak., Lihat: Ensiklopedi Hukum Islam., op.cit., h. 1119 
kebutuhan mendasar manusia di atas, atau dengan kata lain Mengambil kebaikan dari adat atau tradisi, dan menjauhkan hal-hal buruk yang tidak diterima oleh akal sehat, hal ini dibahas secara umum dalam pembahasan makārim al-akhlāk (kemuliaan akhlak) tidak terwujud dan terpeliharanya kebutuhan al-tahsinīyyah ini tidaklah membawa erancamnya eksisternsi agama, jiwa, akal, keturunan, dan harta serta tidak pula membawa kepada kesulitan kelima pokok tersehbut, melainkan dapat menyalahi kepatutan dan menurunkan martabaty pribadi dan masyarakat. Secara umum, maksud syāri' dalam tasyri' hukum Islam adalah "mentahqī " (menetapkan) ${ }^{16}$ kemaslahatan manusia, dengan memenuhi kebutuhan-kebutuhan pokoknya (Darūriyat, hajiyat, Tahsin̄īyāt). Maka setiap hukum syar' '̄ yang ditetapkan, tidak terlepas dari ketiga hal diatas yang bertujuan untuk menegaskan kemaslahatan umat manusia. ${ }^{17}$

Akan tetapi, syari'at yang dibebankan kepada manusia dalam situasi dan waktu tertentu masih terjadi pengecualian, meskipun hal itu dilarang misalnya dalam keadaan darurat, untuk kemaslahatan manusia itu sendiri hal ini sesuai dengan firman Allah QS. al-Baqarah (2) : 286.

Kemudian Para Mujtahid dengan Fiqh mereka dalam syari'at dapat dilihat dalam 5 aspek satu diantara kelima aspek tersebut adalah: Dia mendapatkan sebagaian hukum-hukum syari'at yang sudah jelas akan tetapi ia tidak bisa mengetahui alasan diperintahkan hukum tersebut dan tidak mengetahui hikmah hukum tersebut, maka ia merasa tidak mengetahui hikmat syari' yang terkandung dalam masalah tersebut maka ilmu yang dimilikinya tidak sebanding dengan hukum syari' at. $^{18}$

Manusia tidak mungkin dapat melaksanakan sesuatu dengan baik apabila tidak ia ketahui atau tidak memahami apa maksud dari tujuan Allah sebagai Pencipta Syari'at. Dan manusia dituntut memahami dengan baik agar dapat

${ }^{16}$ Ibrahim Mustafa., op.cit., h. 188

17 Abdul Wahhab Khallāf, 'Ilmu al-Uşūli al-Fiqhi, (Cet. XI; Kairo: Maktabah alDa'wah al-Islamiyah, 1397 H/1977 M), h. 197., Lihat juga: Ensiklopedi Hukum Islam, op.cit., h. $1109-1110$

18 Lihat Muh. Tahir ibn 'Asyura, Maqāşidu al-Syārī'ah al-Islamaiyah, (Cet. VIII; Urdun: Dār al-Nafa’ is, 1421 H/2001 H), h. 182-184 
melaksanakan ajaran-ajaran menurut petunjuk yang termaktub dalam nash-nash al-Qur'an, karena yang demikian itu akan membawa kita kepada tetap dalam ketaatan kepada Allah dan Rasul-Nya.

\section{Kesimpulan.}

Dari Pembahasan diatas, maka dapat diambil beberapa kesimpulan, diantaranya:

> Māqāşsid al-Syarī'ah adalah maksud atau tujuan Syāri' (Allah swt.) dalam penetapan syari'ah berupa sekumpulan aturan atau ketentuan yang berisi perintah, larangan hukum, kemudian dijelaskan oleh Rasul-Nya untuk mengatur dan membina serta membatasi tindakan hamba-Nya untuk mencapai tujuan kehidupan, baik di dunia maupun di akhirat.

> Tujuan Syāri' dalam menurunkan syari'at-Nya tidak lain adalah untuk kemaslahatan manusia di dunia dan akhirat, dengan cara memelihara segala yang daruri bagi manusia dalam penghidupan mereka seperti Agama, Jiwa, akal, keturunan dan Harta. Yang terangkum dalam tiga keadaan yaitu : alḍarüriyyah, al-hājiyyah, dan al-tahsīnīyyah yang apabila tidak terlaksana maka kehidupan manusia akan hancur dan merugi baik dunia dan akhirat.

\section{DAFTAR PUSTAKA}

Ahmad Rofiq, Hukum Islam di Indonesia, (Ed. I, Cet, 6; Jakarta: PT. RajaGrafindo Persada, 2003

'Asyura,Muh. Tahir. Maqāşidu al-Syarī’ah al-Islamiyah. Cet. VIII; Urdun: Dār alNafa'is, $1421 \mathrm{H} / 2001 \mathrm{M}$

Al-Hudāriy. Uşūl al-Fiqh. Cet. III; Beirut: Dar al-Fikr, 1981.

Al-Mişri, Abū al-Fadl Jamaluddin Muhammad Ibn Makram Ibn Mandzur ibn al-Afriqi. Lisan al-Arab. Juz. XIII., Cet. III; Bairut: Dār al-Fikr, 1414 h/1994M.

Al-Syāţibi, Abū Ishāq Ibrahim bin Musa al-lakhmi al-Garnathi al-Māliki. Al-Muwāfakāt fi Uşūli al-Syarī’ah. Juz II., t.Cet; Beirut: Dār al-Qutub al-ilimiyah, t.th.

Kementrian Urusan Agama Islam, Wakaf, Da'wah dan Irsyad Kerajaan Saudi Arabia, AlQur'an dan Terjemahannya, (t. Cet; Madinah: Percetakan al-Qur'an al-Karim Raja Fahd, 1426H), h.157. 
Khallāf, Abdul Wahhāb. 'Ilmu al-Uşūli al-Fiqh. Cet. XI; Kairo: Maktabah al-Da'wah alIslamiyah, $1397 \mathrm{H} / 1977 \mathrm{M}$.

Manan, Dr., SH., S.IP., M.Hum., Reformasi Hukum Islam di Indonesia Ed.I. Cet. I; Jakarta: PT RajaGrafindo, 2006.

Minhajuddin, Prof. DR. H., Pengembangan Metode Ijtihad Dalam Perspektif Fikih Islam. Pidato Pengukuhan Guru Besar Tetap Dalam Ilmu Fikih / Usul fikih Pada Fakultas Syari'ah IAIN “Alauddin”. Disampaikan pada Rapat Senat Terbuka Luar Biasa IAIN Aluddin Makassar hari/tanggal : Senin 31 Mei 2004.

Mustafa, Ibrahim. et. al., Al-Mu'jam al-Wasīţ. Juz. II., t.Cet; Istanbul: al-Maktabat alIslamiyah, 1972M/1392H.

Syalthut, Mahmud, Prof Dr., Al-Islāmu Äqidatun wa Syarī'atun. Cet. III; Mesir: Dār alQalam, 1966. Diterjemahkan oleh Ir. Abdurrahman Zain. Islam, Aqidah dan Syari'ah. Jakarta: Pustaka Amani, 1989.

Syaltut, Mahmud al-Islām aqidah wa Syāri’ah , Mesir: Dār al-Qalam, 1966

Tim Penyusun. Ensiklopedi Hukum Islam. Jilid 4 Cet. V; Jakarta: PT. Ichtiar Baru van Hoeve, 2001).

Zahra, Muhammad Abū. Uşūl al-Fiqh. Diterjemahkan oleh Saifullah Ma'shum. Usul Fikih. Jakarta: Pustaka Firdaus, 1994.

Zaidān, Abdul Karīm, DR., Al-Wajīzu fì Uşūli al-Fiqh. Cet. I; t.t.: Nasyru Iṇsān, t.th. 